\title{
Promoting Resilience in Nurses Caring for Patients with Psychiatric Disorders
}

\author{
Hala Ahmed Elsayes ${ }^{1}$, Ayat Saif Elyazal Abdelraof ${ }^{2}$ \\ ${ }^{1}$ Assistant professor of Psychiatric and Mental Health Nursing, Faculty of Nursing, Tanta \\ University, ${ }^{2}$ Lecturer of Psychiatric and Mental Health Nursing, Faculty of Nursing, Tanta \\ University
}

\begin{abstract}
Nurses working at psychiatric hospital are in challenging and a potentially high stress. The impact of stress and professional challenges can lead to harmful impacts for those nurses as burnout or physical and mental health problems. Resilience is a positive adaptation to nurses' stress management ability and mental wellbeing. The aim of this study is to promote the resilience among nurses caring for patients with psychiatric disorders. Setting: the study was conducted at Tanta Mental Health Hospital. Subjects: 60 nurses were recruited in the study. Tool: it was composed of two main parts: part1: Socio Demographic characteristics and work experience data were developed by the researchers. Part 2: The Connor-Davidson Resilience Scale (CD-RISC) is a self-rated assessment of stress coping ability. The scale was developed based on concepts of hardiness, adaptation, and stress endurance. It is 25 items, all of which carry a 5-point range of responses. Total sum scores range between 0-100, with higher scores indicating greater perceived resilience. Result: There was a statistically significant difference between total means scores of (CD-RISC) scale pre and post-program (8.632 $\mathrm{P}<$ 0.05). The studied psychiatric nurses had moderate resilience mean score pre- program, while, the means score of resilience was high post education program. Conclusion: the resilience health education program is an effective tool in promoting the resilience. Recommendation: Further research should be collaborated about work environments is an important factor to improve resilience and promote an effective work atmosphere for the nurses and suggesting mentorship programs in order to improve resilience by improving positive and supportive professional relationships, emotional insight, life balance and spirituality.
\end{abstract}

Keywords: nurse, psychiatric hospital, resilience, stressors, caring psychiatric patient. 


\section{Tanta Scientific Nursing Journal}

\section{Introduction}

Healthcare professions' work is associated with high levels of stress ${ }^{(1)}$. This stress can negatively influence physical and mental wellbeing (2). Nurses who are caring patients with psychiatric disorders facing substantial stressors and professional challenges. They are at a higher risk for experiencing stress because of working in direct contact with those patients in a potentially high stress settings ${ }^{(3)}$. Such stress brings them various physical, mental, and behavioral problems such as boredom, fatigue, and reduced effectiveness. These problems, in turn, can decrease the quality of their nursing care services and hence, negatively influence patient outcomes ${ }^{(4)}$.

Resilience is among the factors behind nurses' stress management ability and mental wellbeing. It is the ability to successfully cope with threats and the confidence individual has in his/her capabilities to overcome tensions, using effective coping strategies, protect dignity, and promote emotional stability (5). In addition to resilience refers to an individual's ability to keep going well in facing of stressful, conflicting situations. It is mentioned as a developmental process as much as an individual characteristic and individual's ability to adjust ${ }^{(6)}$.
Resilience is the ability of the individuals to bounce back or to cope well in spite of adverse events". Sometimes, it is rapid, confusing and de-stabilizing and tests individuals' adaptive skills ${ }^{(7)}$. There are various forms of resilience. Psychological resilience involves the use of a range of meta-cognitive and emotional processes in protecting nurses from the negative effects of stress. Psychological resilience has been widely investigated for more than four decades in several 'waves' of enquiry. The initial focus was on protective factors and personal characteristics that helped individuals adapt to risk. Further enquiry identified resilience processes and environmental factors influencing people's capacity to adapt. Later enquiry involved development of resilience- building interventions of resilience in the workplace $^{(8)}$.

Nurse encounter various traumatic situations particularly due to distressing and stressful work life. Therefore, it is important for nurse to strengthen their resilience in coping with various difficulties, adapting to new situations, having positive future expectations and protecting their work and daily life. (9) In this context, the nurse who uses her personal characteristics is more likely to minimize the pace of hard work, pressure 


\section{Tanta Scientific Nursing Journal}

and responsibilities by becoming a resilient professional $^{(10)}$.

Patients with psychiatric disorders are attending to the psychiatric hospitals with psychological crisis or disorders of behaviors, that demanding professional nurse to be sensitive, conscious, attentive and ready to cope with the unpredictability clinical conditions. ${ }^{(11)}$ As a consequence, nurses are exposed to a lot of physical and psychological work overloads, which lead to suffering and occupational stress. Nurses are facing another problem related to organizational issues such as insufficient human resources and materials for adequate efficient care. All of these factors may contribute to stress, burnout and attrition $^{(12) .}$

Nursing is by nature as stressful occupation especially when work with patients at psychiatric hospital e.g. demanding relationships from patients with psychiatric disorders and

their relatives, emergency cases and high work burden (13). As a result, nurses in psychiatric hospital have an unusual work environment that includes confined spaces, the potential risk of conflict between patients with the associated risk of physical and mental abuse by aggressive patients, and the need to isolate or seclude patients to avoid harming themselves or other people. ${ }^{(14)}$
Despite being exposed to adverse circumstances, strategies to stay healthy are developed which can make satisfaction with the environment and promoting biopsychosocial well-being. However, some nurses suffer from mental illness problems due to inability to cope with occupation strains. In this sense, resilience is linked to the understanding of risk and protection factors. Risk factors decrease the possibility of overcoming deficiencies; however, their impact is reduced by protective factors ${ }^{(11) .}$

Nurses face many risk factors that call for resilience. Insufficient professional skills and knowledge, coping with stress and utilize emotions, and supportive network from colleagues, and less positive expectations about the future and emotional preparation for the job, are among the many direct or indirect difficult situations nurses encounter ${ }^{(15)}$. These are all risk factors lead to have negative effects on nurses' physical and psychological health and cause exhaustion, psychological problems, reduced job and life satisfaction, and cause leaving or considering leaving the occupation. ${ }^{(16,19)}$

Resilience are grounded on a strengths based model, whereby the focus on the factors that promote life success and achievement, rather than eliminating the factors that promote failure. So, 
administrators in various institutions should organize courses, seminars, conferences, panels, workshops and structured educational programs such as stress management and resiliency training cognitive behavioral therapy and art therapy are reported to effectively improve the personal skills that affect resilience ${ }^{(20-21)}$. In addition, most of the studies conducted in other countries to analyze the factors that influence nurses' resilience and determine strategies to improve resilience were qualitative, practice-oriented and experimental studies, and they carried out structured educational programs to improve resilience in schools and workplaces ${ }^{(22-24)}$.

\section{Significance of the problem}

In recent years, resilience has had a potential impact on health, well-being, quality of life and a factor linked to job satisfaction for nurses. So, nurses with a high degree of resilience will have skills in communicating and problem solving. They also will be able to manage strong feeling and emotional reactions to situations and challenges. Resilience doesn't make problem go away, but it can give the nurse ability to see past her difficulties and feel less stressed. Although many of these nurses did not succumb to the pressure of the job; rather, they remained enthusiastic, sensitive and competent in their clinical approach to treatment. A resilient nurse can cope with stress and may be suitable for mental health work. As a result, resilience has become

a major concern for researchers. So, the aim of the study is to: Promote resilience in nurses Caring for Patients with Psychiatric Disorders.

\section{Research hypothesis:}

1-Directional hypothesis: A health Educational program will have positive effects on nurses' resilience in caring patients with psychiatric disorders.

2-Null hypothesis: A health Educational program will haven't any positive effects on nurses' resilience in caring patients with psychiatric disorders.

\section{Subjects and Method}

\section{Study design:}

The study followed a quasi-experimental study design.

\section{Research setting:}

The study was conducted at Tanta Mental Health Hospital. The hospital is operated by the Ministry of health and population; it has 50 beds. The hospital wards are divided into two free wards (one of males and one of females) and two private wards (one of males and one of females).

This hospital serving the population of the Delta Governorate, Egypt 
Study population and sampling technique:

A convenient sample of 60 nurses working at Tanta Mental Health Hospital. The subjects of this study were selected according to the following criteria; nurses who provide a direct care to patients with psychiatric disorders and who agree to participate in the study. The total numbers of nurses who work at the hospital were 92 nurses. 32 nurses were excluded from the study for many reasons such as, nurses in sick leave or on vocation during data collection were excluded from the study. The final research subjects of sixty nurses who accepted to participate in the study. The nurses working in this setting consist of professional staff such nurses graduated from Faculty of nursing, Technical Health Institute and secondary Nursing School working directly with patient.

\section{Tool of the study}

The Connor -Davidson Resilience Scale (CD-RISC) (Connor \& Davidson 2003). ${ }^{(25)}$

\section{Part I:Socio Demographic characteristic} and work experience data developed by the researchers. Data about nurses will included age, residence, gender, educational level, work history qualifications, years of experience in nursing, years of experience in care of psychiatric patients, exposure to violence in work, work place stress and its effect on health and absenteeism.

Part II: The Connor-Davidson Resilience Scale (CD-RISC) (Connor \& Davidson 2003). The CD-RISC contains 25 items measuring personal competence and acceptance of self and life, all of which carry a 5-point range of responses, as follows: not true at all (0), rarely true (1), sometimes true (2), often true (3), and true nearly all of the time (4). The scale is rated based on how the subject has felt over the past month. The total score ranges from 0 100 , with higher scores reflecting greater resilience.

\section{The scoring system is;}

Low $0>50$, Moderate or average 50-75 and High resilience score $<75-100$.

\section{Method}

1. An official letter was issued from faculty of nursing, Tanta University to study setting to obtain his permission for data collection.

2. Tools of the study and the program were translated into Arabic language by the researchers and were tested for content validity by a jury of five experts in the field of psychiatric nursing to ascertain the appropriateness of items for measuring what they are supposed to measure and both tool and program were proved to be valid. 


\section{Ethical consideration:}

a. Written consent for voluntary participation was obtained from all nurses participating in the study.

b. The subjects were informed about the aim of the study and reassured about the confidentiality of any obtained information and used only for the purpose of the study.

c. Respecting the right of the study subjects to refuse to participate or to withdraw from the study at any phase was emphasized.

d. The nature of the study not produces harm for subjects

4. A pilot study was carried out before embarking in the field of work on $10 \%$ from total subjects to ascertain the clarity and applicability of the study tool. Also it served to estimate the approximate time required for filling study tool as well as to identify obstacles that might be faced during data collection. After collecting pilot study, it was found that each nurse took 15- 20 minutes to fulfill tool of the study and no modification was done on study tool. The pilot subjects were excluded later from actual study sample.

5. Internal consistency of the study tool was done by means of Cronbach's
Alpha coefficient, which yielded values of $r=0.924$

6. The data was collection over a period seven months started from January2019 to July 2019.

7. Actual study: The actual study was divided into the four phases;

I) Phase one: - Assessment phase (pretest)

- Tool of the study was distributed on the study subjects in individual basis and the subjects were asked to fill the questionnaire in the presence of researchers for any clarification and filling of the questionnaire ranged from 15 to 20 minutes, this phase aimed to determine the study subject's needs as a base line of education program.

II) Phase two: - Development of the educational program

- Educational program was developed by the researchers based on reviewing of the recent related literatures and the result of phase one. The program content was developed, the content stressed mainly on (theoretical knowledge about resilience and many skills that help to promote resilience of nursing in caring patients with psychiatric disorders. 
- The program objective was settled according to session content.

- General objective:

Promote

resilience in nurses Caring for Patients with Psychiatric Disorders.

- Specific objective: By the end of this program, the studied nurses will be able to:

- Recognize purpose of the program

- Define the concept of resilience

- Identify psychological resilience and the type of it

- List the importance of resilience to psychiatric nurse

- Discus the positive resilience,

- Determine methods of acquiring it, and

- Apply the different skills that promote resilience to nurses caring patients with psychiatric disorders.

- Lecture, hand out, power point, role play for simulated scenario, group discussion, visual material, audio material and audio visual material were used as teaching method in implementation of education program

- The program was developed on small group basis. The researcher took 4 subgroups/ two days / week one ( on Saturday\& Thursday) in the morning from 9am to10.30am in the morning and the second from $12 \mathrm{pm}$ to $1.30 \mathrm{pm}$ in afternoon,
- The subjects encompassed 8 subgroups. Each sub group composed of 6-8 nurses. Each sub group attended 8 sessions; these sessions were scheduled as 2 sessions per week for duration of 4 weeks. The time for each session was about (60$90 \mathrm{~m})$.

\section{III) Phase three: - Implementation of} education Program.

- The researchers divided the implementation phase of the program into 7 sessions

- First Session: it was an introductory and orientation session that emphasizes on building trust relationship, explanation of the program purpose and significant problem to the nurses in caring patient with psychiatric disorders. At the end of the session the researchers distributed the schedule of the program include; sub-groups, the days, the time/ hours and the outlines of the educational program.

- Second Session: The sessions covered knowledge about the concept of resilience, identify psychological resilience, the type of it and characteristic of person's resilience. 
- Third session: from this session to the last, each session divided into two parts ; first part, one researcher interpreted the theoretical part( knowledge about topic), then the second researcher help the nurses how are applying the skill in their life and during the working with patients. The sessions cover topic "autonomy, self-confidence, selfefficacy and "time management"

- Fourth sessions: it covers topic "therapeutic communication and skills", "humor and hope". The researchers gave examples and discussed the nurses experience (problems) faced during work with patients and other professional staff in psychiatric hospital. Scenario to qualified nurses when deal effectively with patients and use effective caring behavior skills.

- Fifth session: it covers topic "assertiveness, its techniques and the important for nurses".

The second topic is "Cognitive Coping Strategies". At the end of the session the researchers gave homework to the nurses helping them use cognitive coping strategies both aware weak and strong points in the personality and use it to deal with stress.
- Sixth session: Training exercises are done to help nurses to cope

- with stress. It covered the topic "Deep breathing exercise" and "progressive relaxation technique explanation steps of these exercises.

- Seventh session: This session focused on helping the nurses to participate in spiritual practices as spend time in meditation and practice listening to soft music. The researcher informs the patient about the meaning of meditation, characteristics of meditation and steps of implementing meditation.

- Eighth session: The researcher review the topics covered by the group and feedback from the group members about the program.

- At the end of the program for each subgroup, printed booklet of the educational program was given to all studied nurses.

- During implementation of the program, as a general

- The researchers were the initiator, provider and encourage of exchange knowledge, problems, stressors between studied nurses and researchers, and encouraged exploration of their issues and responses. They also acted as a group 
leader who operated as a facilitator, teacher, and trainer.

- The researchers allowed nurses to think critically and give wide range of their own responses to the situations and analyze each one

- All over the sessions, the researchers were motivating the nurses to share in the discussion, and emotionally reward by positive comments and appreciation.

- Each session the researchers gave the nurses the chance to mention positive changes that acquired from the previous sessions.

\section{IV phase four (Evaluation phase):-}

- This concerned with the evaluation of the implemented educational program. The tool of the study was reapplied twice on all study subjects on an individual basis.

- Immediately after implementation of the educational program.

\section{Statistical Analysi}

The collected data were organized, tabulated and statistically analyzed using SPSS software (Statistical Package for the Social Sciences, version 19, SPSS Inc. Chicago, IL, USA). For quantitative data, the range, mean and standard deviation were calculated. For qualitative data, which describe a categorical set of data by frequency, percentage or proportion of each category, comparison between two groups and more was done using Chisquare test $\left(\chi^{2}\right)$. For comparison between means of two groups of parametric data of independent samples, t-test was used. For comparison between means of two related groups (pre and post education program data) of parametric data, paired t-test was used. For comparison between more than two means of parametric data, $F$ value of ANOVA test was calculated.

\section{Results}

Table (1): shows Socio-demographic characteristics of staff nurses in psychiatric departments. It was observed that among the studied nurses, the highest frequency of nurses were female $(83.3 \%)$, nearly half of staff nurses (40\%) aged 30-<40years, In relation to level of education, $43.3 \%$ and $26.7 \%$ were bachelors and diploma degree respectively. In relation to years of experience in psychiatric department, $66.7 \%$ had experience $\geq 10$ years and $70 \%$ of studied subjects had total experience more than ten years. It was observed that the highest frequency of nurses $(40.0 \%)$ working from 30 to less 40 hours. In relation to exposure to violence in work, $65.4 \%$ of the nurses were exposed to verbal work violence, and more than half $(57.7 \%)$ of them reported exposure to work violence from the patients. Also, it was found that $73.3 \%$ of nurses were thinking about work leave from job due to stress 
related to nature of work, and the majority of them (86.7) were hospitalized in the last three months.

Table (2): describes the relationship between mean scores response of the studied subjects about resilience scale pre and post implementing educational program. It was found a significant improvement in nurses' resilience mean score regarding the ability to adapt to change from $2.67 \pm 1.08$ to3.23 \pm 0.89 and the difference was statistically significant $P$ $<0.002)$. Also, there was significant improvement regarding nurses 'under pressure, focus and think clearly, prefer to take the lead in problem solving, control of your life and think of self as strong person at $\mathrm{p}<0.0001^{*}$ post educational program

Table (3): illustrates total scores of Connor-Davidson Resilience Scale (CDRISC) of the studied psychiatric nurses' pre and post an educational program. It was found the studied psychiatric nurses had improvement in resilience mean score post program implementation. There was significant improvement of the total mean score of resilience post education program than pre-program $(81.63 \pm 7.85$ and $62.13 \pm 15.6$ respectively). The difference, resilience score, was statistically significant $(\mathrm{P}<0.05)$.
Figure (1): shows the levels of resilience score of the studied nurse's pre and post implementing educational program in relation to total mean scores. It observed that the levels of resilience were moderate in pre education and post education program

Table (4): the total scores of ConnorDavidson Resilience Scale (CD-RISC) post than pre education program among the studied psychiatric nurses the in relation to their working data. It observed that there was significant improvement change of the nurse's exposure to the types of violence and absenteeism from work due to work pressure after education program at $\mathrm{p}$ $<0.001$ 
Table (1): Socio-demographic and work experiences of the studied nurses.

\begin{tabular}{|c|c|c|c|}
\hline "Variables & & $\begin{array}{c}\text { The studie } \\
\text { n }\end{array}$ & $\underset{\%}{\operatorname{arses}(n=60)}$ \\
\hline Age years & $20-<30$ & $\begin{array}{ll}14 \\
\end{array}$ & 23.3 \\
\hline & $30-<40$ & 24 & 40.0 \\
\hline & $40-<50$ & 20 & 33.3 \\
\hline & $\geq 50$ & 2 & 3.3 \\
\hline Sex & Male & 10 & 16.7 \\
\hline & Female & 50 & 83.3 \\
\hline Residence & Urban & 26 & 43.3 \\
\hline & Rural & 34 & 56.7 \\
\hline Marital status & Unmarried & 10 & 16.7 \\
\hline & Married & 50 & 83.3 \\
\hline Have children & Yes & 50 & 83.3 \\
\hline & No & 10 & 16.7 \\
\hline Education level & Diploma & 16 & 26.7 \\
\hline & Technical Institute & 14 & 23.3 \\
\hline & Bachelor & 26 & 43.3 \\
\hline & Master & 4 & 6.7 \\
\hline years of experience in & $1-<5$ & 2 & 3.3 \\
\hline psychiatry dep. & $5-<10$ & 18 & 30.0 \\
\hline & $\geq 10$ & 40 & 66.7 \\
\hline years of experience & $1-<5$ & 2 & 3.3 \\
\hline & $5-<10$ & 16 & 26.7 \\
\hline & $\geq 10$ & 42 & 70.0 \\
\hline$\overline{\text { Working hours per week }}$ & $20-$ & 4 & 6.7 \\
\hline & $30-$ & 42 & 40.0 \\
\hline & $40-$ & 14 & 23.3 \\
\hline Exposure to violence in & Not occur & 8 & 13.3 \\
\hline work & One/month & 12 & 20.0 \\
\hline & Once/week & 10 & 16.7 \\
\hline & Once/day & 6 & 10.0 \\
\hline & Many times/year & 18 & 30.0 \\
\hline & More and more & 6 & 10.0 \\
\hline If yes, type of violence & Physical violence & 10 & 19.2 \\
\hline & Verbal violence & 34 & 65.4 \\
\hline & Sexual harassment & 8 & 15.4 \\
\hline If yes, personnel of violence & Friends & 12 & 23.1 \\
\hline & Patients & 30 & 57.7 \\
\hline & Patients' families & 10 & 19.2 \\
\hline Time needed to reach work & Half hour or less & 18 & 30.0 \\
\hline & Half to one hour & 20 & 33.3 \\
\hline & More than one hour & 22 & 36.7 \\
\hline Absenteeism due to work & Yes & 20 & 33.3 \\
\hline pressure & No & 40 & 66.7 \\
\hline Think about work leave & Yes & 22 & 36.7 \\
\hline due to work pressure & No & 38 & 63.3 \\
\hline Think about work leave & Yes & 16 & 26.7 \\
\hline $\begin{array}{l}\text { due to stress related to } \\
\text { nature of work }\end{array}$ & No & 44 & 73.3 \\
\hline $\begin{array}{llll}\text { work } & \text { stress } & \text { lead } & \text { to }\end{array}$ & Yes & 38 & 63.3 \\
\hline deterioration of your health & No & 22 & 36.7 \\
\hline Have you been hospitalized & Yes & 8 & 13.3 \\
\hline in the last 3 months? & No & 52 & 86.7 \\
\hline
\end{tabular}




\section{Tanta Scientific Nursing Journal}

Table (2): Relationship between mean scores response of the studied subjects about resilience scale pre and post implementing educational program $(n=60)$.

\begin{tabular}{|c|c|c|c|c|}
\hline \multirow[t]{3}{*}{$\begin{array}{l}\text { Resilience Scale (CD-RISC) items } \\
\text { (Each item was scored }\end{array}$} & \multicolumn{2}{|c|}{$\begin{array}{c}\text { Response of the studied psychiatric } \\
\text { nurses about resilience scale } \\
\text { resilience pre and post education } \\
(n=60)\end{array}$} & \multirow[t]{3}{*}{ t value } & \multirow[t]{3}{*}{ 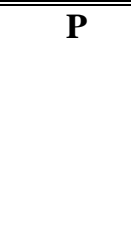 } \\
\hline & Pre-program & Post-program & & \\
\hline & Mean \pm SD & Mean \pm SD & & \\
\hline 1-Able to adapt to change & $2.67 \pm 1.08$ & $3.23 \pm 0.89$ & 3.130 & $0.002 *$ \\
\hline 2-Close and secure & $2.97 \pm 0.88$ & $3.53 \pm 0.59$ & 4.123 & $0.0001 *$ \\
\hline 3-Sometimes fate or God can help & $2.77 \pm 0.87$ & $3.72 \pm 0.55$ & 7.126 & $0.0001 *$ \\
\hline 4-Can deal with whatever comes & $2.47 \pm 1.13$ & $3.32 \pm 0.81$ & 4.738 & $0.0001 *$ \\
\hline $\begin{array}{l}\text { 5-Past success gives confidence for new } \\
\text { challenge }\end{array}$ & $2.63 \pm 1.12$ & $3.50 \pm 0.70$ & 5.082 & $0.0001 *$ \\
\hline 6-See the humorous side of things & $2.53 \pm 1.13$ & $3.23 \pm 0.93$ & 3.715 & $0.0001 *$ \\
\hline 7-Coping with stress strengthen & $2.33 \pm 1.05$ & $3.18 \pm 0.72$ & 5.153 & $0.0001^{*}$ \\
\hline $\begin{array}{l}\text { 8-Tend to bounce back after illness or } \\
\text { hardship }\end{array}$ & $2.67 \pm 0.98$ & $3.32 \pm 0.72$ & 4.115 & $0.0001 *$ \\
\hline 9-Things happen for a reason & $3.27 \pm 0.73$ & $3.58 \pm 0.53$ & 2.711 & $0.008 *$ \\
\hline 10-Best efforts no matter what & $2.60 \pm 1.21$ & $3.45 \pm 0.75$ & 4.631 & $0.0001^{*}$ \\
\hline 11-You can achieve your goals & $2.37 \pm 1.18$ & $3.25 \pm 0.79$ & 4.814 & $0.0001 *$ \\
\hline $\begin{array}{l}\text { 12-When things look hopeless, I don't } \\
\text { give up }\end{array}$ & $2.43 \pm 1.06$ & $3.27 \pm 0.73$ & 4.997 & $0.0001 *$ \\
\hline 13-Know where to turn for help & $2.57 \pm 1.18$ & $3.28 \pm 0.80$ & 3.878 & $0.0001 *$ \\
\hline $\begin{array}{l}\text { 14-Under pressure, focus and think } \\
\text { clearly }\end{array}$ & $1.90 \pm 1.05$ & $3.02 \pm 1.06$ & 5.774 & $0.0001 *$ \\
\hline $\begin{array}{l}\text { 15-Prefer to take the lead in problem } \\
\text { solving }\end{array}$ & $2.27 \pm 0.78$ & $3.17 \pm 0.83$ & 6.140 & $0.0001 *$ \\
\hline 16-Not easily discouraged by failure & $2.33 \pm 1.14$ & $2.98 \pm 1.08$ & 3.197 & $0.002 *$ \\
\hline 17-Think of self as strong person & $2.20 \pm 1.12$ & $2.92 \pm 1.08$ & 3.576 & $0.001 *$ \\
\hline 18-Make unpopular or difficult decisions & $2.20 \pm 1.23$ & $3.02 \pm 1.14$ & 3.765 & $0.0001 *$ \\
\hline 19-Can handle unpleasant feelings & $2.07 \pm 1.10$ & $3.08 \pm 0.98$ & 5.340 & $0.0001^{*}$ \\
\hline 20-Have to act on a hunch & $2.47 \pm 1.29$ & $3.13 \pm 0.95$ & 3.219 & $0.002 *$ \\
\hline 21-Strong sense of purpose & $2.10 \pm 1.05$ & $3.53 \pm 0.81$ & 8.349 & $0.0001^{*}$ \\
\hline 22-In control of your life & $2.50 \pm 1.03$ & $2.97 \pm 0.80$ & 2.764 & $0.0007^{*}$ \\
\hline 23-I like challenges & $2.37 \pm 1.23$ & $3.30 \pm 0.85$ & 4.824 & $0.0001 *$ \\
\hline $24-Y o u$ work to attain your goals & $2.63 \pm 0.84$ & $3.37 \pm 0.88$ & 4.665 & $0.0001 *$ \\
\hline 25 -Pride in your achievements & $2.83 \pm 1.04$ & $3.28 \pm 0.84$ & 2.594 & $0.011^{*}$ \\
\hline
\end{tabular}

*Significant $(\mathbf{P}<\mathbf{0 . 0 5})$ 
Table 3: Levels of resilience of the studied nurse's pre and post implementing educational program in relation to total mean scores $(n=60)$

\begin{tabular}{|c|c|c|c|c|}
\hline \multirow{2}{*}{ Level of scores } & \multicolumn{2}{|c|}{ Pre } & \multicolumn{2}{c|}{ Post } \\
\cline { 2 - 5 } & $\mathbf{N}$ & $\mathbf{\%}$ & $\mathbf{N}$ & $\mathbf{\%}$ \\
\hline mild & 6 & 10.0 & 2 & 3.3 \\
\hline Moderate & 16 & 26.7 & 26 & 43.3 \\
\hline high & 32 & 53.3 & 38 & 63.3 \\
\hline Total & 60 & 100.0 & 60 & 100.0 \\
\hline Range & \multicolumn{2}{|c|}{$18.0-84.0$} & \multicolumn{2}{|c|}{$60.0-98.0$} \\
Mean \pm SD & $62.13 \pm 15.64$ & & $81.63 \pm 7.85$ \\
\hline Paired t-test & \multicolumn{5}{|c|}{0.0001 * } \\
\hline P-value & \multicolumn{5}{|c|}{} \\
\cline { 2 - 5 } &
\end{tabular}

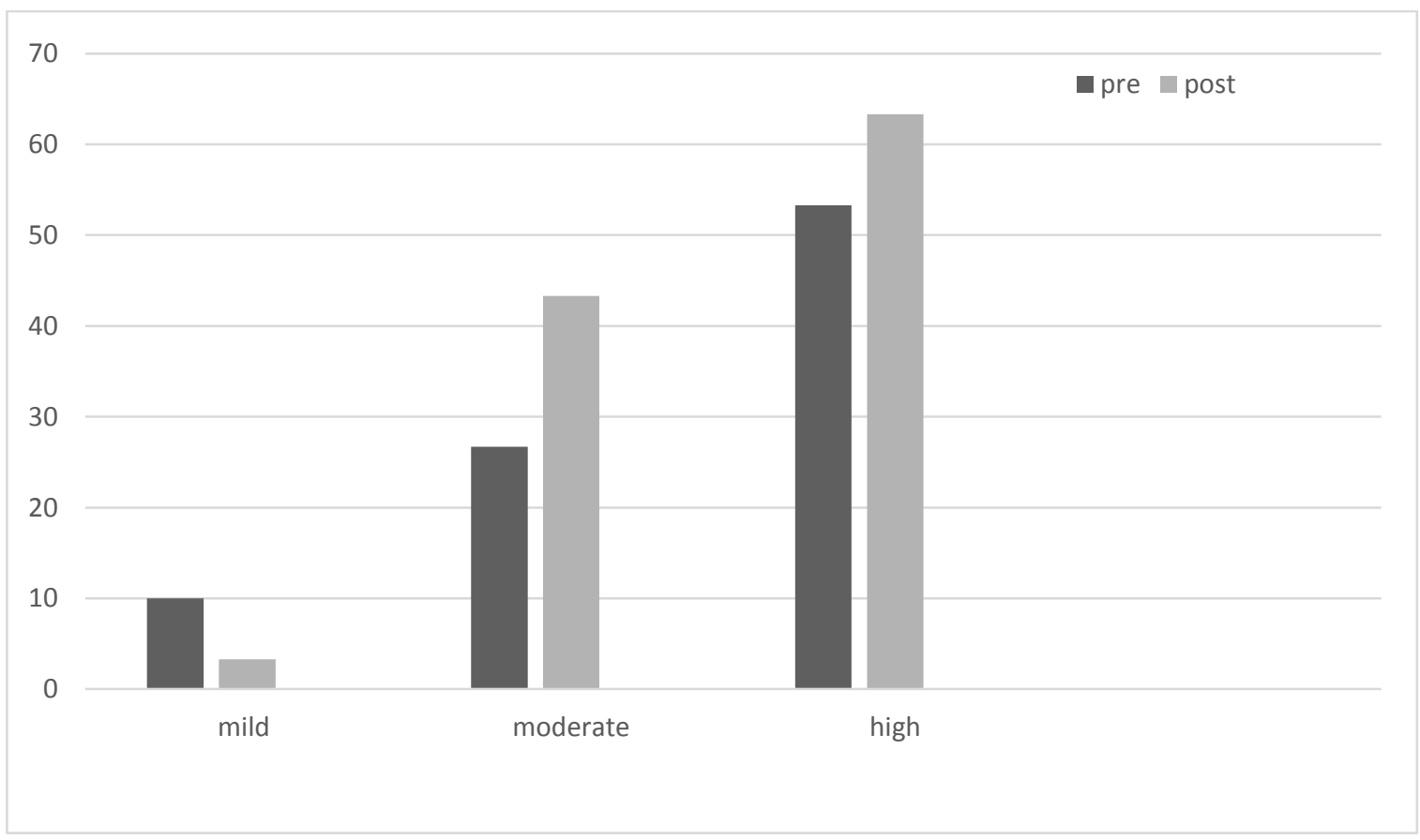

Figure 1: Levels of resilience of the studied nurse's pre and post implementing educational program in relation to total mean scores

*Significant $(\mathbf{P}<\mathbf{0 . 0 5})$

Mild: $0>50$

Moderate or average: 50-75

High resilience score $:<75-100)$ 
Table (4): the total scores of Connor-Davidson Resilience Scale (CD-RISC) post than pre education program among the studied psychiatric nurses the in relation to their working data $(\mathrm{n}=60)$.

\begin{tabular}{|c|c|c|c|c|c|c|c|}
\hline \multirow{3}{*}{\multicolumn{2}{|c|}{ Variables }} & \multicolumn{6}{|c|}{ Total scores of CD-RISC among the studied psychiatric nurses } \\
\hline & & \multicolumn{3}{|c|}{ Post } & \multicolumn{3}{|c|}{ Pre } \\
\hline & & Mean \pm SD & $\begin{array}{l}\text { t-test } \\
\text { or f } \\
\text { test }\end{array}$ & $\mathbf{P}$ & Mean \pm SD & $\begin{array}{l}\text { t-test } \\
\text { or f } \\
\text { test }\end{array}$ & $\mathbf{P}$ \\
\hline \multirow{3}{*}{$\begin{array}{c}\text { Experience } \\
\text { years in } \\
\text { psychiatry dep. }\end{array}$} & $1-<5$ & $58.00 \pm 0.00$ & \multirow{3}{*}{0.255} & \multirow{3}{*}{0.776} & $57.00 \pm 1.41$ & \multirow{3}{*}{0.229} & \multirow{3}{*}{0.796} \\
\hline & $5-<10$ & $64.78 \pm 9.64$ & & & $63.83 \pm 10.34$ & & \\
\hline & $\geq 10$ & $62.25 \pm 18.10$ & & & $61.62 \pm 17.90$ & & \\
\hline \multirow{3}{*}{$\begin{array}{l}\text { Total } \\
\text { experience } \\
\text { years }\end{array}$} & $1-<5$ & $71.00 \pm 0.00$ & \multirow{3}{*}{0.279} & \multirow{3}{*}{0.757} & $70.00 \pm 1.41$ & \multirow{3}{*}{0.255} & \multirow{3}{*}{0.776} \\
\hline & $5-<10$ & $63.00 \pm 7.92$ & & & $61.94 \pm 8.60$ & & \\
\hline & $\geq 10$ & $62.43 \pm 18.08$ & & & $61.94 \pm 17.94$ & & \\
\hline \multirow{3}{*}{$\begin{array}{l}\text { Working hours } \\
\text { per week }\end{array}$} & $20-$ & $71.50 \pm 7.51$ & \multirow{3}{*}{0.71} & \multirow{3}{*}{0.496} & $71.25 \pm 7.23$ & \multirow{3}{*}{0.829} & \multirow{3}{*}{0.442} \\
\hline & 30- & $61.81 \pm 15.79$ & & & $63.14 \pm 17.00$ & & \\
\hline & 40- & $63.57 \pm 16.98$ & & & $60.93 \pm 15.70$ & & \\
\hline \multirow{6}{*}{$\begin{array}{c}\text { Exposure to } \\
\text { violence in work }\end{array}$} & Not occur & $68.50 \pm 10.86$ & \multirow{6}{*}{1.905} & \multirow{6}{*}{0.109} & $67.87 \pm 10.83$ & \multirow{6}{*}{1.85} & \multirow{6}{*}{0.119} \\
\hline & One/month & $69.00 \pm 7.60$ & & & $68.42 \pm 7.63$ & & \\
\hline & Once/week & $67.80 \pm 7.87$ & & & $66.60 \pm 8.58$ & & \\
\hline & Once/day & $56.67 \pm 25.07$ & & & $56.17 \pm 25.5$ & & \\
\hline & $\begin{array}{c}\text { Many } \\
\text { times/year }\end{array}$ & $55.44 \pm 19.76$ & & & $54.83 \pm 19.48$ & & \\
\hline & $\begin{array}{l}\text { More and } \\
\text { more }\end{array}$ & $63.33 \pm 10.17$ & & & $62.33 \pm 11.06$ & & \\
\hline \multirow{3}{*}{$\begin{array}{l}\text { If yes, type of } \\
\text { violence }\end{array}$} & $\begin{array}{l}\text { Physical } \\
\text { violence }\end{array}$ & $70.20 \pm 12.59$ & \multirow{3}{*}{7.145} & \multirow{3}{*}{$0.002 *$} & $69.50 \pm 13.48$ & \multirow{3}{*}{5.913} & \multirow{3}{*}{$0.005^{*}$} \\
\hline & $\begin{array}{c}\text { Verbal } \\
\text { violence }\end{array}$ & $64.33 \pm 11.96$ & & & $62.41 \pm 12.05$ & & \\
\hline & $\begin{array}{c}\text { Sexual } \\
\text { harassment }\end{array}$ & $46.00 \pm 24.76$ & & & $46.00 \pm 24.76$ & & \\
\hline \multirow{3}{*}{$\begin{array}{c}\text { If yes, personnel } \\
\text { of violence }\end{array}$} & Friends & $66.00 \pm 9.86$ & \multirow{3}{*}{0.43} & \multirow{3}{*}{0.652} & $62.83 \pm 9.40$ & \multirow{3}{*}{0.087} & \\
\hline & Patients & $62.50 \pm 19.56$ & & & $61.03 \pm 19.64$ & & 0.917 \\
\hline & $\begin{array}{l}\text { Patients' } \\
\text { families }\end{array}$ & $60.57 \pm 9.41$ & & & $60.00 \pm 11.06$ & & \\
\hline
\end{tabular}

Vol. 19 No. 2 November, 2020 
Tanta Scientific Nursing Journal

\begin{tabular}{|c|c|c|c|c|c|c|c|}
\hline \multirow{2}{*}{$\begin{array}{c}\text { Absenteeism } \\
\text { from work due } \\
\text { to work } \\
\text { pressure }\end{array}$} & Yes & $53.00 \pm 19.98$ & \multirow{2}{*}{-3.827} & \multirow{2}{*}{$0 * * *$} & $52.35 \pm 19.61$ & \multirow{2}{*}{3.796} & \multirow{2}{*}{$0.0001 * *$} \\
\hline & No & $67.80 \pm 10.11$ & & & $67.02 \pm 10.44$ & & \\
\hline \multirow{2}{*}{$\begin{array}{c}\text { Think about } \\
\text { work leave due } \\
\text { to work } \\
\text { pressure }\end{array}$} & Yes & $59.27 \pm 13.45$ & \multirow{2}{*}{-1.362} & \multirow{2}{*}{0.179} & $58.54 \pm 13.40$ & \multirow{2}{*}{1.362} & \multirow{2}{*}{0.179} \\
\hline & No & $64.95 \pm 16.64$ & & & $64.21 \pm 16.61$ & & \\
\hline \multirow{2}{*}{$\begin{array}{c}\text { Think about } \\
\text { work leave due } \\
\text { to stress related } \\
\text { to nature of } \\
\text { work }\end{array}$} & Yes & $61.25 \pm 16.39$ & \multirow[b]{2}{*}{-0.479} & \multirow[b]{2}{*}{0.634} & $60.75 \pm 16.30$ & \multirow[b]{2}{*}{0.41} & \multirow[b]{2}{*}{0.683} \\
\hline & No & $63.45 \pm 15.55$ & & & $62.64 \pm 15.55$ & & \\
\hline \multirow{2}{*}{$\begin{array}{l}\text { work stress lead } \\
\text { to deterioration } \\
\text { of your health }\end{array}$} & Yes & $61.11 \pm 17.75$ & \multirow[t]{2}{*}{-1.147} & \multirow[t]{2}{*}{0.256} & $60.47 \pm 17.68$ & \multirow[t]{2}{*}{1.082} & \multirow[t]{2}{*}{0.284} \\
\hline & No & $65.91 \pm 10.94$ & & & $65.00 \pm 11.08$ & & \\
\hline \multirow{2}{*}{$\begin{array}{c}\text { Have you been } \\
\text { hospitalized in } \\
\text { the last } 3 \\
\text { months? }\end{array}$} & Yes & $61.50 \pm 21.01$ & \multirow{2}{*}{-0.263} & \multirow{2}{*}{0.794} & $61.37 \pm 20.92$ & \multirow{2}{*}{0.146} & \multirow{2}{*}{0.884} \\
\hline & No & $63.08 \pm 14.94$ & & & $62.25 \pm 14.92$ & & \\
\hline
\end{tabular}

\section{*Significant $(\mathbf{P}<0.005)$}




\section{Tanta Scientific Nursing Journal}

\section{Discussion}

Psychiatric Nurses may often struggle with stressors, but there are many stressors in the work environment, as work exhaustion, task disputes, lack of time, poor job-related interpersonal relationships, feeling powerless to provide quality care, struggling with competing demands. In addition, conflict with physicians, peers group and supervisors, and inadequate emotional preparation, stressful, traumatic, or difficult situations for nurses. These types of situations can also cause physical as well as mental problems, such as fatigue, irritability, lack of concentration, unhappiness, depressive sensation, and emotional readiness. Despite all of these challenges, resilience enables nurses to cope with their work stresses and to maintain healthy and stable psychological functioning. In this respect, it is likely to say that resilience is a protective agent with nurses' physical and mental wellbeing. $(26,27)$ So, appropriate steps to help them build their resilience must be taken.

The current study revealed that, one third of the staff nurses in psychiatric hospital were exposed to work violence, more than half of them reported exposure to work violence from the patients and about two third of the subject exposed to verbal violence. These results may be related to more than one factor, as patients involuntarily admitted to the hospital with different psychiatric disorders and symptoms, also, the necessarily high level of nurses-patient contact increases the exposure of the nurse to the risk. Other factors, ward environments that increase the risk of violence include an overloaded and a stressful ward atmosphere, crowding, locked units, and a lack of therapeutic activities. On the other hand, nursing staff factors that increase susceptibility to patients' violence include inadequate social skills, poor teamwork, and low tolerance nursing work, poor communication, and excitement by patients.

Anderson (28) stated that nurses in psychiatric wards and emergency areas are at the highest risk of suffering from workplace violence, probably because the necessarily high level of nurses-patient contact increases the exposure of the nurse to the hazard. Also, study in Saudi Arabia about workplace violence against nurses in psychiatric hospital settings by Basfr et al ${ }^{(29)}$ reported that the prevalence of violence in psychiatric hospital against nurses was $90.3 \%$, of which more than half of them had been exposed to both physical and verbal violence and violent behavior was exhibited mainly by the patients themselves (81.3\%). By contrast, Whittington and Wykes ${ }^{(30)}$ proposed a 
cyclical model of mental health violence for mental health nurses and suggested that nurses who were not available to patients were at higher risk for assault, while nurses who spent more time in the patient's place were less at risk.

Also, it was found that more than two third of nurses were thinking about work leave from job due to stress related to nature of work; and the majority of them were hospitalized in the last three months. These may be related to nurses' perception of the risk of the assault by patients during care, negative relationship between nurses and supervisory support, Job stress can be caused the harmful physical and emotional response that occurs when the requirements of the job do not match the capabilities that lead to dissatisfy with job. This result is in congruent with study of Zaki (31) exposes that the majority of psychiatric nurses are feeling that they are pressured by patients' demands, feeling that patients are negative about them, and feeling that there are patients threatening and making them afraid. Another study by Yoshizawa (32), who conveyed that the nurses who had faced with verbal abuse had fear to communicate with patients at psychiatric hospital. In another study in Saudi Arabia by Basfr et al (29), reported in that the majority of psychiatric nurses felt either stress or anxiety, while other felt depressed and few of them were not interested in attending work and were considering leaving their job as the result of their exposed to violence .

Regarding the total resilience scores of the studied nurse's pre and post implementation of resilience program, it was found improvement of the total mean score of studied psychiatric nurse's resilience post education program than preprogram; The improvement in the resilience skills may be related to the studies nurse were not clearly know the meaning of resilience before this study when the researchers assess their knowledge about resilience. Also, the nurse can improve some skills in their self as autonomy, self-confidence, selfefficacy, humor and hope. So, the studies nurse was interesting to promote their resilience in caring the psychiatric patients and respond effectively to the education program. Therefore, understanding this process of resilience enables developing strategies to promote resilience for helping those caring patients in psychiatric hospitals. so the researchers gave the nurses session interpreted the concept of psychological resilience as a means to adapt to different stressor and stress in the workplace, Factors related to it, positive flexibility and characteristics of individuals with psychological resilience. In addition 


\section{Tanta Scientific Nursing Journal}

to the ability of the individual to problem solve, cognitively appraise adverse situations, adaptive behavior and selfmastery were learned and developed with targeted strategies.

McDonald et al; $2013^{(33)}$ concluded that nurse's self-confidence, self-mindfulness, communication and problem solving skills were improved

after training program related to resilience. In the same line, Craigie et al . 2016. ${ }^{(34)}$. Additionally; Edward, 2010; (35) in his study with mental health professionals, revealed that resilience is a product of autonomy, responsibility and confidence, and a result of using creativity, flexibility, and humour in the work environment. In contrary to this result, study by Pines al. 2014; (36) who reported that there no significant differences were found between pre and post-test in his study, after taught topics including resiliency and behaviours of resilient nurses, professional empowerment, conflict management and teamwork to the nurses.

In the current study, there were other causes behind improvement of the total mean score among studied psychiatric nurse's resilience following the education program than pre-program, implementation of communication skills as empathy, active listening skills, silence, questionnaire, broad opening, and assertiveness. Also, the researcher shows videos and scenario bring to light how the nurses deal effectively with the patients and use effective caring behavior skills, the researchers played role of nurse and studied nurses played role of patient to make role play of effective and therapeutic response between nurse and patients while giving care to psychiatric disorder patients. In addition, they offered

session for improve self- esteem and time management to nurses, during this sessions the nurses were interested and try practice the session in caring the patient $\mathrm{s}$ with psychiatric disorders and in their life . the researches were giving the time to the studied nurses to discuss with them about what was done and nurses problems that face them in practice and the researcher were found solution as repeat interpret some points or gave examples for alternative intervention to some cases . This in agreement with Gerhart et al 2016; $\left({ }^{37)}\right.$ conducted an awareness based communication training in order to improve resilience of medical staff Improvement of the levels score of resilience among studied psychiatric from moderate to high may be related to the researcher introduced

sessions for stress management (breathing exercise, progressive muscle relaxation, meditation, exercise and cognitive 
strategies) to teach and train nurses about method to manage stress. This agree with intervention program by Chesak, Bhagra, Schroeder, Foy et al (2015) (38) who illustrated that the stress and anxiety scores reduced, also, awareness resilience scores increased in the experimental group and the nurses had positive approaches towards the effect of the stress management and resilience education program.

The study show that total score of resilience post education program among studied nurses in relation to working data was improved, It observed that there was significant improvement change of the nurse's exposure to the types of violence and absenteeism from work due to work pressure after education program this may the experience in research work helped nurses have a critical thinking and an experience in dealing stressful situation in work environment.in the line research by

Dehvan F. et al 2018. founded that psychiatric nurses'

resilience can be promoted through managing their physical and psychological stress and promoting their mental health ${ }^{(39)}$ The current result represented an effective attempt to enhance the capacities of nurses through personal resilience. The researchers used future

strategies that may reduce nurses 'emotional fatigue, fading morale, discouragement and burnout. Finally, this finding suggested that building and enhancing resilience may be a professional as well as a personal asset that improves workplaces as a whole.

\section{Conclusion}

\section{Based on the results of the present} study, it can be conducted that there was marked significant improvement in the total resilience scores for the studied nurse after implementation of resilience education program. It was found that studied psychiatric nurses had moderate resilience score. while, the means score of resilience was high post education program.

\section{Recommendation}

Based on the result of the study the following recommendations are presented:

- Further research about work environments is an important factor to improve resilience and promote an effective work atmosphere for the nurses.

- Research is needed to understand the important of resilience for nurses in clinical education.

- Assess the knowledge of undergraduate nurses to resilience is needed and increase the awareness about the benefits of resilience to nurses.

- Introduce the concept of resilience in the curriculum of nursing courses in 
particular psychiatric nursing, as well as improve key skills of resilience in order to build students resilience and protect graduates against problems in the clinical.

- Postgraduate education programs should include subjects to improve personal skills such as "establishing positive interpersonal relationships, flexible, critical and creative thinking, self-efficacy, altruism, use of humor, protecting personal and professional ethical borders, emotional intelligence, problem solving and coping skills.

- Nurses should spare time for exercise, yoga and meditation, listening to music, reading, or photography to improve coping skills. These programs should also be organized in institutions and nurses should be encouraged to attend them.

\section{References}

1. Mazlom SR, Darban F, Vaghei S, Modarres gharavi M, Kashani lotfabadi M, Shad M. The effect of Stress Inoculation Program (SIP) on nurses' Perceived stress in psychiatric wards. Evidence Based Care. 2012;2(1):35-44.

2. Sharma J, Dhar RL, Tyagi A. Stress as a mediator between work-family conflict and psychological health among the nursing staff: Moderating role of emotional intelligence. Applied Nursing Research. 2016; 30:268-75.

3.varasteh mogaddam $Y$, sadeg fard $M$, mohammadi $\boldsymbol{H}$. Stressors and coping strategies of psychiatric nurses iin psychatric wards. Journal of Nursing Education. 2013;1(3):54-61.

\section{Wang SM, Lai CY, Chang YY, Huang} CY, Zauszniewski JA, Yu CY. The relationships among work stress, resourcefulness, and depression level in psychiatric nurses. Archives of psychiatric nursing. 2015;29(1):64-70.

5.Khoshknab M, Bakhshi E. The Effect of Emotional Intelligence (EI) Training on Nurses' Resiliency in Department of Psychiatry. Iranian Journal of Psychiatric Nursing (IJPN). 2016;3(12):28-37.

\section{Pinquart M. Moderating}

effects of dispositional resilience on associations between hassles and psychological distress. Philipps University of Marburg2009. 53-60.

7. Rutter M. Developing concepts in developmental psychopathology.In: Developmental psychopathology and wellness: Genetic and environmental influences, Hudziak J (ed.), 2008, American Psychiatric Publishing, Washington, DC.

8. Ribeiro RP, Martins JT, Marziale MHP, Robazzi MLCC. Work-related 
illness in nursing: an integrative review.

Rev Esc Enferm USP. 2012;46(2):495504.

9. Souza SRC, Oliveira EB, Mauro MYC, Mello R; Kestemberg CCF, Paula GS.

Nursing workloads in hospitalization unit mental health and worker health. Rev Enferm UERJ. 2015; 23 (5): 633-8.

10. Fischborn AF, Viegas MF. The activity of nursing workers in a hospital: between norms and renormalizations. Work Educ Salud. 2015; 13 (3): 657-74.

11. Sousa VFS, Araujo TCCF. Occupational stress and resilience among health professionals. Psicol Ciênc Occupation. 2015; 35 (3): 90015.

12.Omori, H. (2015): Development of the Psychiatric Nurse Job Stressor Scale (PNJSS), Psychiatry and Clinical Neurosciences; 65: 567-575

13.Yada, H.(2015): The supplement to Developing the Psychiatric Nurse Job Stressor Scale, Int J Nurs Clin Pract. Japan, 2: 145

14.Kane, P.(2012): $\quad$ stress causing psychiatric illness among nurses. j occup envnt med ;13(1) .available from www.ijoem.com

15. Gillespie BM, Chaboyer W, Wallis M, Grimbeek $\boldsymbol{P}$. Resilience in the operating room: developing and testing of a resilience model. J Adv Nurs 2007; 59:427-38.

16. Zander M, Hutton A, King L. Coping and resilience factors in pediatric oncology nurses. J Pediatr Oncol Nurs 2010; 27:94-108.

17. Garcia-Dia MJ, DiNapoli JM, GarciaOna L, Jakubowski R, et al. Concept analysis: resilience. Arch Psychiatr Nurs 2013; 27:264-70.

18. Cameron F, Brownie S. Enhancing resilience in registered aged care nurses. Australas J Ageing 2010; 29:66-71.

19. Gillespie BM, Chaboyer W, Wallis M. The influence of personal characteristics on the resilience of operating room nurses: a predictor study. Int J

Nurs Stud 2009;46: 968-76.

20. Jackson D, Firtko A, Edenborough M Personal resilience as a strategy for surviving and thriving in the face of workplace adversity: a literature review. J Adv Nurs ,2007; 60: 1-9.

21. Gessler R, Ferron L . When caregiving ignites burnout - New ways to douse the flames. American Nurse Today.2012

22. Cheak S. Integration and Impact of Stress Management and Resiliency Training (Smart) in a Nurse Residency 
Program: A Feasibility Study. Theses and Dissertations 2013:347.

23. McDonald G, Jackson D, Wilkes L, Vickers MH. A work-based educational intervention to support the development of personal resilience in nurses and midwives. Nurse Educ Today 2012; 32:378-84.

24. Cusack L, Smith M, Hegney D, Rees CS, et al. Exploring Environmental Factors in Nursing Workplaces That Promote Psychological Resilience: Constructing a Unified Theoretical Model. Front Psychol 2016; 7:600.

25-Kathryn M. Connor, M.D., nand Jonathan R.T. Davidson, M.D. development of a new resilience scale: the connor-davidson resilience scale (cd-risc) depression and anxiety 2003,18:76-82

26- Beauvais AM, Stewart JG, De Nisco S., \& Beauvais, J. E. "Factors related to academic success among nursing students": A descriptive correlation research study. Nurse Education Today. 2014; 34(6), 918-923.

27- Yılmaz EB. Resilience as a strategy for struggling against challenges related to the nursing profession. Chinese Nursing Research 4 (2017) 9-13.

28- Anderson $\boldsymbol{C}$. Workplace violence: are some nurses more vulnerable? Issues
Ment Health Nurs (2002) 23(4):35166. doi:10.1080/01612840290052569.

29- Basfr W, Hamdan A, Al-Habib S. "Violence Against Nurses in Psychiatric Hospital Settings" : Perspectives from Saudi Arabia. SQU Med J. February 2019, Vol. 19, Iss. 1, pp. e19-25, Epub. 30 May 19.

30-Whittington R, Wykes T. "An observational study of associations between nurse behaviour and violence in psychiatric hospitals". J Psychiatric Mental Health Nurs (1994) 1(2):8592. doi:10.1111/j.1365-2850.1994.tb 0002.In Mental Health Nurse's Exposure to Workplace Violence Leads to Job Stress, Which Leads to Reduced Professional Quality of Life Front. Psychiatry, 27 February 2018. https://doi.org/10.3389/fpsyt.20 18.00059 .

31- Zaki, R." Job Stress and Self- Efficacy among Psychiatric Nursing Working in Mental Health Hospitals at Cairo". Journal of Education and Practice. (2016). 7 (20), Pp. 103 -113.

32-Yoshizawa, K. Relationship between occupational stress and depression among psychiatric nurses in Japan. Archives of Environmental \& Occupational Health. (2016). 71, Pp. $10-15$. 
33-McDonald G, Jackson D, Wilkes L, Vickers MH. Personal resilience in nurses and midwives: effects of a work-based educational intervention. Contempy Nurse. 2013;45: 134e143.

\section{4-Craigie M, Slatyer S, Hegney D, et al.} A pilot evaluation of a mindful selfcare and resiliency (MSCR) intervention for nurses. Mindfulness. 2016;7: 764e774.

35-Edwards, D., Burnard, P., Bennett, K., Hebden, $\boldsymbol{U}$., . A longitudinal study of stress and self-esteem in student nurses. Nurse Educ. Today2010, 30 (1), 78-84. https:// doi.org/10.1016/j. nedt.2009.06.008.

36-Pines, E., Rauschhuber, M., Cook, J., Norgan, G., Canchola, L., Richardson, C., Jones, M., . Enhancing resilience, empowerment, and conflict management among baccalaureate students: outcomes of a pilot study. Nurse Educ. 2014,39 (2), $85 \mathrm{e} 90$.

https://doi.org/10.1097/NNE.0000000 000000023.

\section{7-Gerhart J, O'Mahony S, Abrams I,} Grosse J, Greene MM, Levy M. A pilot test of mindfulness-based communication training to enhance resilience in palliative care professionals. J Contextual Behav Sci. 2016;5:89-96.
38-Chesak SS, Bhagra A, Schroeder DR, Foy DA, et al. Enhancing resilience among new nurses: feasibility and efficacy of a pilot intervention. Ochsner J 2015;15:38-44.

39- Dehvan F, KamangarP, Baiezeedy S, Roshani D, Gheshlagh R . Mental health \& resilience among psychiatric nurses. Nursing Practice Today. 2018; 5(4): 368-374. 